\title{
Estimation of Specific Surface Area using Langmuir Isotherm Method
}

\author{
1* ITODO, A U; ${ }^{2}$ ITODO, H U; ${ }^{1}$ GAFAR, M K \\ ${ }^{1}$ Department of Chemistry, Kebbi State University of Science and Technology, Aliero, Nigeria. ${ }^{2}$ Department of \\ Chemistry, Benue State University, Makurdi, Nigeria.
}

\begin{abstract}
A comparison of four widely used linear equations of the Langmuir types of isotherm (The Langmuir Type 1, 2, 3 and 4 ) were examined in an experiment using dye sorption onto derived acid and salt treated Fish Activated Carbon $\left(\mathrm{H}_{3} \mathrm{PO}_{4}-\mathrm{FAC}\right.$ and $\mathrm{ZnCl}_{2}-\mathrm{FAC}$ respectively). Isotherm parameters obtained from the four Langmuir linear equations differed. Though Langmuir type 1 is the most popular form, but the type 2 had the highest coefficient of determination $\left(\mathrm{R}^{2}=0.931-0.984\right)$ compared with the other Langmuir linear equations (with $\mathrm{R}^{2}$ values ranges of $0.696-0.982,0.613-0.926$ and $0.613-0.926$ for Langmuir type 1,3 and 4 isotherm models respectively). 3,7 bis(dimethylamino) phenothiazin-5-ium ion was used to measure the Extent of monolayer coverage $\left(\mathrm{q}_{\mathrm{m}}\right)$ and specific surface areas $\left(\mathrm{S}_{\mathrm{MB}}\right)$ following the application of type 1 isotherm. From this study, Value obtained for the Acid treated carbon $\left(\mathrm{H}_{3} \mathrm{PO}_{4}-\mathrm{FAC}\right.$ with $\left.\mathrm{S}_{\mathrm{MB}} ; 18.170\right)$ is higher than that of the Salt treated carbon, $\left(\mathrm{ZnCl}_{2}-\mathrm{FAC}, \mathrm{S}_{\mathrm{MB}} ; 13.579\right)$ which compared more to that of commercial carbon, $\mathrm{CAC}\left(\mathrm{S}_{\mathrm{MB}}\right.$; 13.884) units in multiple of $10^{-3} \mathrm{~km}^{2} \mathrm{~kg}^{-1}$. The reliability of the Langmuir type 1 and 2 methods seems very good in specific surface area estimation. @JASEM
\end{abstract}

Equilibrium relationships between sorbents and sorbates are described by sorption isotherms which give the capacity of a sorbent for a sorbate (Yuh,2006). Isotherms can be obtained by examining batch reactions at fixed temperatures. Linear regression is frequently used to determine the bestfitting isotherm. In this present study, the linear leastsquares method via the correlation coefficient $\left(\mathrm{R}^{2}\right)$ was used (Yuh,2006).Specific surface area is defined as the accessible area of solid surface per unit mass of material. Because the surrounding phase can modify the surface area, each method that was studied for measuring surface had shortcomings (Chongrak et al.,1998)

The interference by the surrounding phase was especially problematical for the Nitrogen adsorption/desorption isotherm method in which case the entire surface was modified by vacuum dried treatment before Nitrogen adsorption (Chongrak et $a l .$, 1998). This method measures only the external and not the internal surface area. The method of adsorption of methylene blue in liquid phase for specific surface area determination has been adopted widely for various natural solids: activated carbon, charcoal, graphite, and silica, for example. The method of methylene blue adsorption for measuring the specific surface area of fish carbon, as established here, can provide a common reference method for adsorbent characterization in quality control, much like other mechanical properties. The objective was to estimate the specific surface area of derived Fish carbon, to compare, in the future, with the surface area determined by other methods. The Langmuir equation was used to calculate the specific surface area of the adsorbent. The general form of Langmuir isotherm is (Chongrak et al., 1998).
$\mathrm{Y}=\mathrm{KC}_{\mathrm{e}} /\left(1+\mathrm{KC}_{\mathrm{e}}\right)$

where $Y$ is the fraction of fish carbon surface covered by adsorbed methylene blue molecules, $K$ is a constant, and $\mathrm{C}_{\mathrm{e}}$ is the equilibrium methylene blue solution concentration. In this study, $Y=N / N m$, where $N$ (taken as $\mathrm{q}_{\mathrm{e}}$ ) represents the number of moles of methylene blue adsorbed per gram of derived sorbent at equilibrium concentration, $\mathrm{C}_{\mathrm{e}}$, and $\mathrm{Nm}$ is the number of moles of methylene blue per gram of sorbent required to form a monolayer (Taken as $\mathrm{q}_{\mathrm{m}}$ ), with units in $\mathrm{mg} / \mathrm{g}$. After making the substitution and rearranging Eq. 1, it became

$\mathrm{q}_{\mathrm{e}} / \mathrm{q}_{\mathrm{m}}=\mathrm{KC}_{\mathrm{e}} /\left(1+\mathrm{KC}_{\mathrm{e}}\right)$

On rearrangement, equation 2 becomes

$\mathrm{C}_{\mathrm{e}} / \mathrm{q}_{\mathrm{e}}=\left(1 / \mathrm{q}_{\mathrm{m}}\right) \mathrm{C}_{\mathrm{e}}+1 / \mathrm{Kq}_{\mathrm{m}}$

For all adsorption isotherms of methylene blue onto fish carbon, the plot of $\mathrm{C}_{\mathrm{e}} / \mathrm{q}_{\mathrm{e}}$ vs. $\mathrm{C}_{\mathrm{e}}$ gives a straight line with slope equal to $1 / q_{\mathrm{m}}$, and intercept equal to $1 / K q_{\mathrm{m}}$. Therefore, the Langmuir isotherm is an adequate description of the adsorption of the methylene blue onto adsorbent. The specific surface area was calculated by the following equation (Chongrak et al.,1998; Itodo et al.,2010a,b)

$$
\mathrm{S}_{\mathrm{MB}}=\left(\mathrm{q}_{\mathrm{m}} \times \mathrm{a}_{\mathrm{MB}} \times \mathrm{N}_{\mathrm{A}} \times 10^{-20}\right) / \mathrm{M}
$$

$S_{\mathrm{MB}}$ is the specific surface area in $10^{-3} \mathrm{~km}^{2} \mathrm{~kg}^{-1} ; q_{e}$ is the number of molecules of methylene blue adsorbed at the monolayer of fibers in $\mathrm{mgg}^{-1} \cdot \mathrm{a}_{\mathrm{MB}}$ is the occupied surface area of one molecule of methylene blue $=197.2 \AA^{2}$ (Graham, 1955; Ardizzone et al.,2003) ; $\mathrm{N}_{\mathrm{A}}$ is Avogadro's number, $6.02 \times 1023$ $\mathrm{mol}^{-1}$; and $\mathrm{M}$ is the molecular weight of methylene 
blue, $373.9 \mathrm{~g} \mathrm{~mol}^{-1}$. Equation 3 is typical of the Langmuir type 1 isotherm. Other forms are summarized in Table 1.

Table 1: Langmuir Isotherm showing the type 1,2,3 and 4 linear forms

\begin{tabular}{l|l|ll}
\hline Isotherm & General Form & Linear Form & Plot \\
\hline Langmuir Type 1 & & $\mathrm{C}_{\mathrm{e}} / \mathrm{q}_{\mathrm{e}}=\left(1 / \mathrm{q}_{\mathrm{m}}\right) \mathrm{C}_{\mathrm{e}}+1 / \mathrm{Kq}_{\mathrm{m}}$ & $\mathrm{C}_{\mathrm{e}} / \mathrm{q}_{\mathrm{e}} \mathrm{Vs}_{\mathrm{e}} \mathrm{C}_{\mathrm{e}}$ \\
Langmuir Type 2 & $\mathrm{q}_{\mathrm{e}}=\left(\mathrm{q}_{\mathrm{m}} \mathrm{K}_{\mathrm{a}} \mathrm{C}_{\mathrm{e}}\right) / 1+\mathrm{K}_{\mathrm{a}} \mathrm{C}_{\mathrm{e}}$ & $1 / \mathrm{qe}=\left(1 / \mathrm{K}_{\mathrm{a}} \mathrm{q}_{\mathrm{m}}\right) 1 / \mathrm{C}_{\mathrm{e}}+1 / \mathrm{q}_{\mathrm{m}}$ & $1 / \mathrm{q}_{\mathrm{e}} \mathrm{Vs} 1 / \mathrm{C}_{\mathrm{e}}$ \\
Langmuir Type 3 & & $\mathrm{q}_{\mathrm{e}}=\mathrm{q}_{\mathrm{m}}-\left(1 / \mathrm{K}_{\mathrm{a}}\right)\left(\mathrm{q}_{\mathrm{e}} / \mathrm{C}_{\mathrm{e}}\right)$ & $\mathrm{q}_{\mathrm{e}} \mathrm{Vs} \quad\left(\mathrm{q}_{\mathrm{e}} / \mathrm{C}_{\mathrm{e}}\right)$ \\
Langmuir Type 4 & & $\mathrm{q}_{\mathrm{e}} / \mathrm{C}_{\mathrm{e}}=\mathrm{K}_{\mathrm{a}} \mathrm{q}_{\mathrm{m}} \cdot \mathrm{K}_{\mathrm{a}}\left(\mathrm{q}_{\mathrm{e}}\right)$ & $\mathrm{q}_{\mathrm{e}} / \mathrm{C}_{\mathrm{e}} \mathrm{Vs} \quad \mathrm{q}_{\mathrm{e}}$ \\
\hline
\end{tabular}

In this present study, Methylene blue was chosen because of its known strong adsorption onto solids and its recognized usefulness in characterizing adsorptive material (Ardizzone et al.,2003) . It has a molecular weight of $373.9 \times 10^{-3} \mathrm{~kg} \mathrm{~mol}^{-1}$. The structure of this dye is shown in Fig. 1.

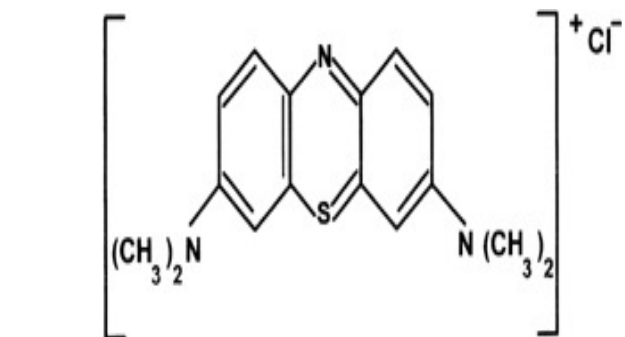

Fig. 1: Structure of 3,7 bis (dimethylamino) phenothiazin-5-ium ion (Methylene blue)

\section{MATERIALS AND METHODS}

Fish (Oreochromis niloticus, popularly called Nile tilapia) of slight spoilage evidence was procured from Sokoto central market. The Fish samples were washed with plenty of water to removes surface impurities, Boiled several time to reduce oil contents, rinsed and sundried. Fish samples were dried in an oven at $100^{\circ} \mathrm{C}$ overnight (Omonhenle et al, 2006) and pulverized, followed by sieving with a $<2 \mathrm{~mm}$ mesh size sieve. The less than $2 \mathrm{~mm}$ samples were stored in airtight containers. A one step Activation process,earlier described elsewhere (Gimba et al., et al.,2001; Itodo et al.,2009a,b,c,d,e) was adopted with slight modification. Approximately $3 \mathrm{~g}$ of each pretreated fish sample, of $<2 \mathrm{~mm}$ mesh size) were mixed separately with $3 \mathrm{~cm}^{3}$ of each $1 \mathrm{M}$ activating agent $\left(\mathrm{H}_{3} \mathrm{PO}_{4}, \mathrm{ZnCl}_{2}\right)$.The sample mixtures were subjected to the furnace at $800^{\circ} \mathrm{C}$ for 5 minutes. The samples were removed, poured into ice water bath, excess water was drained and allowed to stand at room temperature. The procedure was repeated for different residual time $(5 \mathrm{~min}, 10 \mathrm{~min}$ ) for the different activating agents. As a modification. the activated carbon generated above were washed, using $10 \%$ $\mathrm{HCl}$ to removed surface ash, followed by warm water. Rinsing was done with distilled water to removed residual acid. The sample was then dried in an oven at $110^{\circ} \mathrm{C}$ overnight and ball milled into sizes that passes through both $<0.5$ and $<2 \mathrm{~mm}$ sieve .Washing of activated samples was complete when a pH of 6-8 was ascertained (Itodo et al.,2008).

Methylene blue stock (1000mgl-1) and standard solution: Methylene blue; MB (purchased from S.D Chem, Boiser) and obtained as sealed from the chemical store of UDUSOK. The MB was dried at $110^{\circ} \mathrm{c}$ for 2 hours before use. All of the Methylene blue solution was prepared with distilled water. The basic dye (Methylene blue) was used without further purification. (i) A stock solution of $1000 \mathrm{mgl}^{-1}$ was prepared by dissolving $1.127 \mathrm{~g}$ Methylene blue in $1000 \mathrm{ml}$ distilled water (Omomnhenle et al., 2006). This gives the Methylene stock. The experimental solution was prepared by diluting the stock solution with distilled water in the range of $10,15,20,25$ and $30 \mathrm{mgl}^{-1}$. The concentration of MB was determined at $630 \mathrm{~nm}$ by the UV - visible spectrophotometer (Chongrak et al.,1998). A calibration curve of optical densities against methylene blue concentrations was obtained by using standard methylene blue solutions of known concentrations at $\mathrm{pH}$ values between 7 and 8. This was done to verify the wavelength for a $30 \mathrm{mg} / \mathrm{L}$ concentration. An adsorption study was carried out in a batch mode at a predetermined $1 \mathrm{~h}$ interaction time in series of $50 \mathrm{ml}$ conical flasks after agitation.

\section{RESULTS AND DISCUSSION}

The optimum temperature for activation was earlier experimentally determined to be $800^{\circ} \mathrm{c}$ above which high level of residual ash sets in. Result in Tables 2 showed that activation burn off is high with a resultant low \% yield at a longer activation dwell time (10 minutes). The entire results fall within the range for published data (Odebunmi and Okeola, 2001). 
Estimation of Specific Surface Area.....

\begin{tabular}{llll} 
Table 2: Percentage Burn off, \% Yield and Bulk density of Acid and Salt Treated Fish Carbon \\
\cline { 2 - 3 } & Activation burn off $(\%)$ & Yield $(\%)$ & $\begin{array}{l}\text { Bulk density } \\
\left(\mathrm{glcm}^{3}\right)\end{array}$ \\
\hline $\mathrm{H}_{3} \mathrm{PO}_{4}$-FAC /5min & 29.24 & 70.76 & 1.520 \\
$\mathrm{H}_{3} \mathrm{PO}_{4}$-FAC /10min & 37.33 & 62.67 & 1.570 \\
$\mathrm{ZnCl}_{2}$-FAC /5min & 18.42 & 81.58 & 1.710 \\
$\mathrm{ZnCl}_{2}$-FAC /10min & 20.00 & 80.00 & 1.862 \\
\hline
\end{tabular}

$\mathrm{H}_{3} \mathrm{PO}_{4}$-FAC /5min- $\operatorname{acid}\left(\mathrm{H}_{3} \mathrm{PO}_{4}\right)$ treated Fish Activated Carbon at 5mins activation, $\left.\mathrm{ZnCl}_{2}-\mathrm{FAC}_{1} / 10 \mathrm{~min}-\mathrm{Salt}(\mathrm{ZnCl})_{2}\right)$ treated Fish Activated Carbon at 10 mins activation

No considerable impact of activation time on yield is observed for the adsorbent prepared by $\mathrm{ZnCl}_{2}$ modification. On the contrary, activating agents plays a major role as made evidence on Table 2. $\mathrm{ZnCl}_{2}$ treated adsorbent presented higher yield compared to their corresponding Acid treated adsorbent.

Table 3: Langmuir Adsorption Isotherm Experimental Data for Commercial Activated Carbon (CAC).

\begin{tabular}{|c|c|c|c|c|c|c|}
\hline $\mathrm{C}_{\mathrm{o}}$ & $\mathrm{C}_{\mathrm{e}}$ & $\mathrm{q}_{\mathrm{e}}$ & $\mathrm{C}_{\mathrm{e}} / \mathrm{q}_{\mathrm{e}}$ & $1 / \mathrm{q}_{\mathrm{e}}$ & $1 / \mathrm{C}_{\mathrm{e}}$ & $\mathrm{q}_{\mathrm{e}} / \mathrm{C}_{\mathrm{e}}$ \\
\hline 10 & 0.469 & 0.956 & 0.490586 & 1.046025 & 2.132196 & 2.03838 \\
\hline 15 & 0.767 & 1.423 & 0.539002 & 0.702741 & 1.303781 & 1.85528 \\
\hline 20 & 1.119 & 1.888 & 0.592691 & 0.529661 & 0.893655 & 1.687221 \\
\hline 25 & 1.949 & 2.305 & 0.845553 & 0.433839 & 0.513084 & 1.182658 \\
\hline 30 & 6.25 & 4.373 & 1.429225 & 0.228676 & 0.16 & 0.69968 \\
\hline
\end{tabular}

Table 4 : Langmuir Adsorption Isotherm Experimental Data for Acid Treated Fish Carbon $\left(\mathrm{H}_{3} \mathrm{PO}_{4}-\mathrm{FAC}\right)$.

\begin{tabular}{|c|c|c|c|c|c|c|}
\hline $\mathrm{C}_{\mathrm{o}}$ & $\mathrm{C}_{\mathrm{e}}$ & $\mathrm{q}_{\mathrm{e}}$ & $\mathrm{C}_{\mathrm{e}} / \mathrm{q}_{\mathrm{e}}$ & $1 / \mathrm{q}_{\mathrm{e}}$ & $1 / \mathrm{C}_{\mathrm{e}}$ & $\mathrm{q}_{\mathrm{e}} / \mathrm{C}_{\mathrm{e}}$ \\
\hline 10 & 0.933 & 0.906 & 1.029801 & 1.103753 & 1.071811 & 0.971061 \\
\hline 15 & 1.121 & 1.187 & 0.944398 & 0.84246 & 0.892061 & 1.058876 \\
\hline 20 & 1.909 & 1.809 & 1.055279 & 0.552792 & 0.523834 & 0.947617 \\
\hline 25 & 2.856 & 2.214 & 1.289973 & 0.451671 & 0.35014 & 0.77521 \\
\hline 30 & 5.723 & 4.427 & 1.292749 & 0.225887 & 0.174734 & 0.773545 \\
\hline
\end{tabular}

Linear regression is frequently used to determine the best-fitting isotherm, However, the Langmuir isotherm can be linearized as four different types (Table 1), and simple linear regression will result in different parameter estimates The more popular linear forms used are Langmuir-1 and Langmuir- 2, and the best fit is obtained using Langmuir- 2 because of the minimal deviations from the fitted equation resulting in the best error distribution or perfect correlation $\left(\mathrm{R}^{2}=1.00\right)$. Figures 3 to 6 show the four linear Langmuir equations with the experimental data for the sorption of dye onto Fish carbon at various initial concentrations (Co). Values of the Langmuir constants, the saturated monolayer sorption capacity, $\mathrm{q}_{\mathrm{m}}$, and the sorption equilibrium constant, $\mathrm{Ka}$, are presented in Table 5 for the sorption of dye onto Fish carbon at room temperature. These values of the coefficient of determinations, $R^{2}$, obtained from Langmuir-1, indicate that there is strong positive evidence that the sorption of dye onto the adsorbent follows the Langmuir isotherm (Yuh,2006).

The linear analysis using different linear forms of the Langmuir equation will significantly affect calculations of the Langmuir parameters. Table 5 shows typical results of the Langmuir constants. It seems that the Langmuir isotherm obtained from Langmuir-2 provided a better fit to the experimental data.
Specific Surface Area $\left(S_{M B}\right)$ Determination: The typical Langmuir type 1 adsorption isotherm of Methylene blue on Fish carbon represented by equation 3 was made (figure not shown) for commercial activated carbon and figure 3 for the acid treated activated carbon. The type 1 isotherm is generally associated with monolayer adsorption . However, their initial slopes do not lie very close to the $y$-axis. This either shows that the affinity of methylene blue for the adsorbent is moderate or, on the other hand, that this affinity may be ascribed to a Van der Waals force (Yuh,2006). The Langmuir isotherm shows that the amount of methylene blue adsorbed increases as the concentration increases up to a saturation point. Beyond this point, increasing the methylene blue concentration will not cause further increase. This behavior is typical of sorbents with a limited number of accessible sites. As long as there are available sites, adsorption will increase with increasing methylene blue concentration, but as soon as all of the sites are occupied, a further increase in the quantity of methylene blue will result to a negative adsorption (desorption) at the monolayer. The acid treated activated carbon $\left(\mathrm{H}_{3} \mathrm{PO}_{4}-\mathrm{FAC}\right)$ proves to have a higher surface area $\left(\mathrm{S}_{\mathrm{MB}}=\right.$ $18.170 \times 10^{-3} \mathrm{~km}^{2} \mathrm{~kg}^{-1}$ ) than the salt treated fish carbon $\left(\mathrm{S}_{\mathrm{MB}}=13.579 \times 10^{-3} \mathrm{~km}^{2} \mathrm{~kg}^{-1}\right)$ which compares more to that of the commercially available activated carbon 
Estimation of Specific Surface Area.....

$\left(\mathrm{S}_{\mathrm{MB}}=13.884 \times 10^{-3} \mathrm{~km}^{2} \mathrm{~kg}^{-1}\right)$. The trends therefore imply that the level of accessible area of solid surface (Fish carbon) per unit mass of material (Methylene blue dye) follows the order of; $\mathrm{H}_{3} \mathrm{PO}_{4}-\mathrm{FAC}>\mathrm{CAC}$ $>\mathrm{ZnCl}_{2}-\mathrm{FAC}$.

\begin{tabular}{|c|c|c|c|c|c|c|}
\hline Adsorbent & $\begin{array}{l}\text { Langmuir } \\
\text { Isotherm }\end{array}$ & $\begin{array}{l}\text { Equation } \\
(\mathrm{y}=)\end{array}$ & $\mathrm{R}^{2}$ & $\mathrm{q}_{\mathrm{m}}(\mathrm{mg} / \mathrm{g})$ & $\mathrm{K}_{\mathrm{a}}\left(\mathrm{Lmg}^{-1}\right)$ & $\mathrm{S}_{\mathrm{MB}}\left(10^{-3} \mathrm{~km}^{2} \mathrm{~kg}^{-1}\right)$ \\
\hline CAC & $\begin{array}{l}\text { Type } 1 \\
\text { Type } 2 \\
\text { Type } 3 \\
\text { Type } 4\end{array}$ & $\begin{array}{l}0.161 x+0.438 \\
0.402 x+0.185 \\
-0.397 x+2.363 \\
-2.329 x+5.666\end{array}$ & $\begin{array}{l}0.982 \\
0.993 \\
0.926 \\
0.926\end{array}$ & $\begin{array}{l}6.211 \\
5.405 \\
-0.397 \\
2.433\end{array}$ & $\begin{array}{l}0.368 \\
0.462 \\
2.519 \\
2.329\end{array}$ & 13.884 \\
\hline $\mathrm{H}_{3} \mathrm{PO}_{4}-\mathrm{FAC}$ & $\begin{array}{l}\text { Type } 1 \\
\text { Type } 2 \\
\text { Type } 3 \\
\text { Type } 4\end{array}$ & $\begin{array}{l}0.068 x+0.951 \\
0.911 x+0.086 \\
-0.071 x+1.055 \\
-8.634 x+9.925\end{array}$ & $\begin{array}{l}0.696 \\
0.984 \\
0.613 \\
0.613\end{array}$ & $\begin{array}{l}14.706 \\
11.627 \\
-0.071 \\
1.150\end{array}$ & $\begin{array}{l}0.072 \\
0.094 \\
14.085 \\
8.634\end{array}$ & 18.170 \\
\hline $\mathrm{ZnCl}_{2}-\mathrm{FAC}$ & $\begin{array}{l}\text { Type } 1 \\
\text { Type } 2 \\
\text { Type } 3 \\
\text { Type } 4\end{array}$ & $\begin{array}{l}0.191 x+0.456 \\
0.914 x+0.075 \\
-0.197 x+1.400 \\
-4.668 x+6.708\end{array}$ & $\begin{array}{l}0.781 \\
0.931 \\
0.919 \\
0.919\end{array}$ & $\begin{array}{l}5.236 \\
13.333 \\
-9.197 \\
1.434 \\
\end{array}$ & $\begin{array}{l}0.419 \\
0.082 \\
5.076 \\
4.668 \\
\end{array}$ & 13.579 \\
\hline
\end{tabular}

CAC- Commercial Activated carbon, $\mathrm{H}_{3} \mathrm{PO}_{4}$-FAC- Acid treated Fish Activated Carbon, $\mathrm{ZnCl}_{2}$-FAC - Salt Treated Fish Activated Carbon

Monolayer Coverage: The theoretical concept behind the Langmuir are (1) The adsorption is an equilibrium process (2) The adsorption cannot proceed beyond monolayer coverage (3) All sites are equivalent and the surface is uniform i.e the surface is perfectly flat on a microscopic scale. Hence, the ability of a molecule to adsorb at a given site is independent of the occupation of neighbouring sites (Hammaini et al., 2007; Itodo et al.,2010 a,b,c). A confirmation of the fitness of experiment data into Langmuir isotherm model indicates the homogenous nature of the adsorbent surface. The result will also demonstrate the formation of monolayer coverage of dye molecule at the outer layer of the adsorbent (Hammed et al., 2006). $\mathrm{q}_{\max }$ is the maximum sorption uptake. The Langmuir values $\left(\mathrm{q}_{\mathrm{m}}\right)$ from isotherms were related to the maximum adsorption capacity $\left(\mathrm{mgg}^{-1}\right)$ or the saturated monolayer capacity (Yuh,2006) while $\mathrm{K}_{\mathrm{a}}$ is the adsorption energy $\left(\mathrm{Lmg}^{-1}\right.$ ) (Itodo et al.,2010 a,b,c). In this research, $\mathrm{q}_{\mathrm{m}}$ is defined as the amount of adsorbate per unit gram of adsorbent required to to form a monolayer coverage (Chongrak et al., 1998). Results on Table 5 which was based on the best fit isotherm (Langmuir type 2) indicates that the level of monolayer coverage follows the other of $\mathrm{q}_{\mathrm{m}}$ for $\mathrm{ZnCl}_{2}$-FAC (13.333) > $\mathrm{H}_{3} \mathrm{PO}_{4}-\mathrm{FAC}(11.627)>\mathrm{CAC}(5.405) \mathrm{mg} / \mathrm{g}$. It thus implies that the maximum adsorption capacity of adsorption onto a uniform surface follows the said trends or order. It also implies that $\mathrm{ZnCl}_{2}$ FAC $\left(\mathrm{q}_{\mathrm{m}} ; 13.333\right)$ exhibit more monolayer adsorption onto a surface containing a finite number of adsorption sites of uniform strategies with less transmigration of adsorbate in the plane surface (Hameed et al., 2006). It also implies that the adsorbent is more homogenous in surface structure, thus, demonstrate also the formation of monolayer coverage of dye molecule at the outer layer of the adsorbent (Hammed et al., 2006). It does not necessarily mean that the adsorbent is better.

Conclusion: It is not appropriate to use the coefficient of determination of the linear regression method for comparing the best-fitting isotherms. Langmuir type 1 is the most-popular linear form but did not present the best fit as a model for dye uptake by derived Fish carbon. Highlights in this analysis showed that the Type 2 isotherm (which had the highest coefficient of determination) could be used in estimating extend of monolayer coverage, The type 1 isotherm is suitable for estimating Specific surface area $\left(S_{M B}\right)$, The type 3 isotherm is difficult to interpret and characterized with negative $\mathrm{q}_{\mathrm{m}}$ values while the type 4 isotherm shared common characteristics with type 1 and 2 . Generally, the adsorption of methylene blue allows the determination of the specific surface area of natural Fish carbon. This work has shown that the method is simple and requires less elaborate apparatus and time than other methods.

Acknowledgements: Authors are grateful to Itodo Praise Udoji for his resources utilized in this analysis and to the Technologists of Agric Soil Science Laboratory of Usmanu Danfodiyo University, Sokoto for donating the furnace and routine apparatus used in this research.

\section{REFERENCES}

Ardizzone, S., G. Gabrielli, and P. Lazzari. (1993). Adsorption of methylene blue at solid/liquid 
and water/air interfaces. Colloids Surfaces76:149-157.

Chongrak K; Eric H; Noureddine A; and Jean P. (1998).Application of Methylene Blue Adsorption to Fiber Specific Surface Area Measurement. J. Cotton Sci. 2:164-173

Gimba C.E. (2001). Adsorption of Methylene Blue by Activated Carbon From Coconut Shell, Global J. Pure Appl. Sci. 4: 765- 767

Graham, D. (1955). Characterization of physical adsorption systems. III. The separate effects of pore size and surface acidity upon the adsorbent capacities of activated carbons. Phys. Chem. 59:896-900.

Hameed, B.H.(2009),Evaluation of Papaya Seed as a Non Conventional Low Cost Adsorbent for Removal of Methylene Blue. Hazard Mat. 162:939-944.

Hameed, B.H; Din, A. M. and Ahmad, A.L. (2006).Adsorption of Methylene Blue onto Bamboo Based Activated Carbon: kinetics and Equilibrium Studies. Hazard Mat. 137(3):695699

Hammaini, A. H; Gonza,F; Ballester,A; Bla'zquez, M.L; Mun, J.A; Gonza, F; Ballester, A; Bla' zquez, M.L. and Munoz, J.A.(2007). Biosorption of Heavy Metals by Activated Sludge and their Desorption Characteristics. J. Environ Mgt. 84: 419-426

Itodo, A.U; Abdulrahman, F.W; Hassan,L.G; Maigandi, S. A(2008).Adsorption capacities and intensities of chemically modified carbon animalis and activated carbon:A comparative study. Int. J Chem.Sci. 1(2):214-220

Itodo,A.U; Happiness,U.O;Obaroh,I.O;Usman,A.U and Audu S.S (2009a).Temkin,R-D,Langmuir and Freundlich adsorption isotherms of industrial dye uptake unto $\mathrm{H}_{3} \mathrm{PO}_{4}$ catalyzed poultry waste bioadsorbent. J. Sci. Technol Res. 8 (1):52-56

Itodo, A.U; Abdulrahman, F.W; Hassan,L.G; Maigandi, S. A and Happiness, U.O (2009b).Estimation of the type of adsorption, sorbent saturation capacities and heat of sorption of poultry droppings activated carbon animalis. Int. J. Nat. Appl Sci 5(1)92-97
Itodo, A.U; Abdulrahman, F.W; Hassan,L.G; Maigandi, S. A and Happiness,U.O (2009c).Performance assessment and isotherm modeling of dye uptake by $\mathrm{H}_{3} \mathrm{PO}_{4}$ and $\mathrm{ZnCl} 2$ modified activated carbon animalis from poultry droppings. Int. J. Trop. Agric. Syst..3 (1):36-42

Itodo,A.U; Abdulrahman,F.W; Hassan, L.G; Maigandi, S. A; Dogonyaro,A.I;Sadiq,I.S. and Happiness,U.O (2009d).Adsorption of methylene blue dye onto Chemically catalyzed carbon animalis. Afr. J. Phys. Sci. 2(2):70-75

Itodo,A.U; Abdulrahman,F.W; Hassan,L.G; A.I.Dogonyaro; I.S.Sadiq and Happiness,U.O (2009e). Biosorption of Heavy metals and herbicides onto poultry based activated carbon animalis. Conference paper presented at the $7^{\text {th }}$ Chemclass conference of the Chemical Society of Nigeria which held on 11/06/2009 at National research Institute for Chemical Technology (NARICT),Zaria - Nigeria.

Itodo A.U., Abdulrahman F.W., Hassan L.G, Maigandi S.A., and Itodo H.U (2010a). Physicochemical parameters of Adsorbents from locally sorted $\mathrm{H}_{3} \mathrm{PO}_{4}$ and $\mathrm{ZnCl}_{2}$ modified Agricultural wastes. New York Sci. 3(5):17-24

Itodo A.U., Abdulrahman F.W., Hassan L.G, Maigandi S.A., and Itodo H.U (2010b). Application of Methylene Blue and Iodine Adsorption number for the Measurement of Specific Surface area by four acid and salt treated activated carbon. New York Sci $3(5): 25-33$.

Itodo,A.U; and Itodo, H.U. (2010c). Sorbents capacities and intensities of Thermochemically Cracked Shea nut Shells for the Removal of Waste water Dyestuff. Acad. Arena 2(3):41-50.

Odebunmi, E. and Okeola, F. (2001). Preparation and Characterization of Activated Carbon From Waste Material. Chem Soc. Nig. 26 (2): 49-155.

Omomnhenle, S; Ofomaja, A. and Okiemen, F.E. (2006). Sorption of Methylene Blue by Unmodified and Modified Citric Acid Saw Dust. Chem Soc. Nig. 30 (1 \& 2): 161- 164.

Yuh, H.(2006). Isotherms for the Sorption of Lead onto Peat: Comparison of Linear and NonLinear Methods. Pol. J. Environ Stud. 15(1) : 81-86 